Original Research

\title{
Logistics of the Electronic Waste Sampling Procedure: The Influence of Granularity on Determination of Copper Content in PCBs
}

\author{
Martina Laubertova ${ }^{1}$, Jarmila Trpcevska ${ }^{1}$, Marcela Malindzakova ${ }^{2 *}$ \\ ${ }^{1}$ Technical University of Kosice, Institute of Recycling Technology, Kosice, Slovakia \\ ${ }^{2}$ Technical University of Kosice, BERG Faculty, Institute of Logistics, Kosice, Slovakia
}

Received: 12 July 2017

Accepted: 17 September 2017

\begin{abstract}
Analytical data on material waste are usually obtained through analysis of samples that represent an insignificant portion of the investigated material mass. Therefore, for the obtained measurement data to be a reliable source of information, and not only analytical disinformation, the collected samples must be representative of the investigated waste material. Waste electric and electronic equipment (WEEE) is considerably heterogeneous material with a high content of copper. The test sample designated for the chemical analysis must truly represent the WEEE from which it was collected. The aim of this study was to develop an acceptable sampling procedure to investigate the composition of heterogeneous printed circuit boards; where the influence of grain size on the precision of chemical analysis of printed circuit boards waste (PCBs) stemming from mobile phones (MPs) has been investigated. Based on the chemical analysis of copper content in the sample (the highest metal content in PCBs) with grain size $(\mathrm{d} \leq 200 \mu \mathrm{m})$, copper content was $15.5 \%$ and dispersion was 1.62 , which showed the highest accuracy of chemical analysis.
\end{abstract}

Keywords: WEEE, sampling procedure, PCBs

\section{Introduction}

As the market continues to expand and innovation cycles become shorter, the replacement of consumer equipment accelerates, making electrical and electronic equipment (EEE) a fast growing source of waste. According to the European Union, waste electrical and electronic equipment (WEEE) is one of the target areas to be regulated in regards to the application of the principles of prevention, recovery, and safe disposal of waste.

*e-mail: marcela.malindzakova@tuke.sk
The EU is trying to contribute to sustainable production and consumption, where as a first priority, the re-use, recycling, and other forms of recovery of such wastes are stated in order to contribute to an efficient use of resources and to the retrieval of valuable secondary raw materials. In 2008, $65 \%$ of EEE placed on the market had already been separately collected, but more than half of this amount was potentially the object of improper processing and illegal exports, and even when properly processed, such waste was not reported. This led to losses of valuable secondary raw materials to environmental degradation and to inconsistent data records [1].

At present, a high level of attention (in practice and in research) focuses mainly on the processing of printed 
Table 1. Content of metals in ores and PCBs [2].

\begin{tabular}{|c|c|c|c|c|}
\hline \multirow{2}{*}{ Metal } & \multicolumn{3}{|c|}{ Content $\%$} & \multirow{2}{*}{$\begin{array}{c}\text { Price (USD/t) } \\
02 / 02 / 2016\end{array}$} \\
\cline { 2 - 5 } & Ores & High-grade material & Low-grade material & 4,600 \\
\hline $\mathrm{Cu}$ & $0.5-1.0$ & $7-20$ & $3.4-21$ & 14.950 \\
\hline $\mathrm{Sn}$ & $<1$ & $2.9-4.9$ & $0.72-1.4$ & $\begin{array}{c}\text { Price (USD/oz.) } \\
02 / 02 / 2016\end{array}$ \\
\hline \multicolumn{3}{|c|}{ Content (ppm) } & $10-20$ & $115-280$ \\
\hline $\mathrm{Au}$ & $5-7$ & $16-566$ & $4-10$ & \\
\hline $\mathrm{Pd}$ & $5-7$ & $189-1,380$ & $3-210$ & \\
\hline
\end{tabular}

circuit boards (PCBs) from discarded computers and mobile phones. The main reason is that these boards contain noteworthy quantities of metals and are therefore a lucrative commodity called "high-grade material." Table 1 compares the content of metals in PCBs to the content of metals in primary raw materials. The high prices of the valuable metals clearly justifies the recycling of PCB materials as a significant source of secondary raw materials.

Obtaining a sample (i.e., sampling) is the first step in analyzing WEEE for the presence of certain materials. Hence an effective sampling strategy is required. International standard [3] does not provide comprehensive guidance on each and every product that could be classified as electrotechnical equipment. Analytical research is usually labor- and time-consuming as well as expensive, and thus its result should provide authoritative and reliable information. Due to this fact, it is necessary to properly prepare the waste samples for content analysis.

The sampling and assaying processes are being continuously innovated in close collaboration with the suppliers; most such technologies are developed "inhouse." Since there is no standard reference material available for sampling of PCB waste, this article wishes to contribute to this particular area and propose an applicable sampling process.

Sampling and primary sample preparation of electronic waste in Umicore Hoboken company in Belgium is performed by a stream sampler (400 kg), then by milling in a knife mill $(\mathrm{d} \leq 6000 \mu \mathrm{m})$, followed by the actual sampling with a rotary sampler $(4 \mathrm{~kg})$. The final sample preparation is done by drying, milling, and filtering to a grain size of between 0.1 to $0.3 \mathrm{~mm}(1.5 \mathrm{~kg})$. The next step includes packing and sealing the samples into $100 \mathrm{~g}$ bags, where subsequently 16 such samples are sent to the customer and into the lab. A spare sample is kept as a back-up [4-5].

For example, the referenced authors [6] gathered 10 samples of printed wiring boards (PWB), where different electronic devices were selected for the study, including the PWB from mobile phones. The printed wiring boards, including all mounted components such as semiconductors, resistors, capacitors, and so on, were cut into $3 \times 3 \mathrm{~cm}$ pieces and subsequently milled to a grain size of $(\mathrm{d} \leq 250 \mu \mathrm{m})$ by a combination of cutting and centrifugal mills while the material was cooled by liquid nitrogen. Since there is no standard reference material

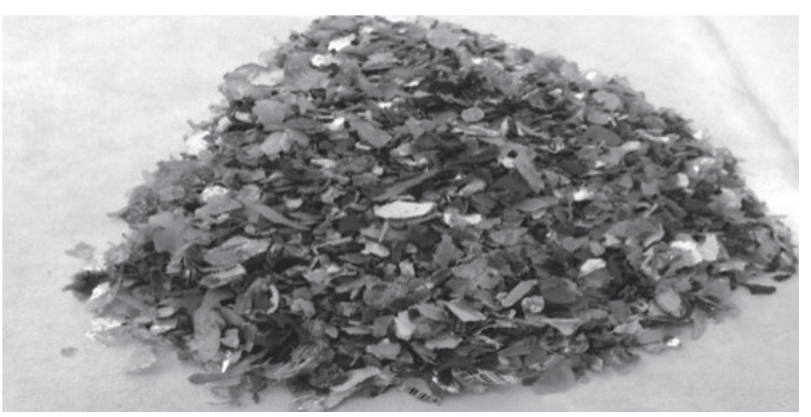

Fig. 1. Grain fraction $(\mathrm{d} \leq 2,000 \mu \mathrm{m})$.

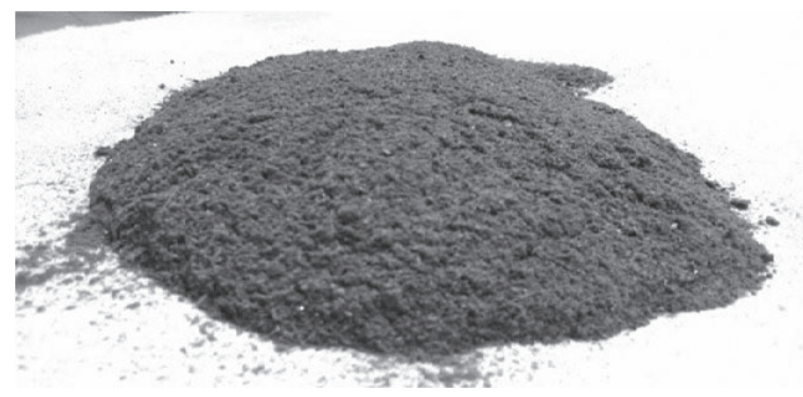

Fig. 2. Grain fraction $(\mathrm{d} \leq 1,000 \mu \mathrm{m})$.

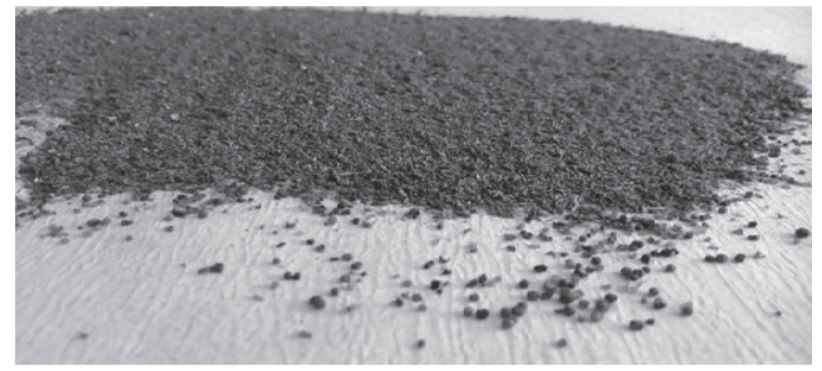

Fig. 3. Grain fraction $(\mathrm{d} \leq 420 \mu \mathrm{m})$. 
available for printed wiring boards, a "model reference material" was created by mixing different reference materials (RMs). A microwave sample preparation was used to digest the samples. Since a grain size of $250 \mu \mathrm{m}$ was used, the minimum sample mass had to be set to more than $1.2 \mathrm{~g}$, considering that accuracy of less than $15 \%$ for trace elements was required.

The printed circuit board samples were crushed in a hammer mill followed by sieving with the help of a mesh opening grates set to less than $4 \mathrm{~mm}$ for PCB-MP. Material was quartered into four samples of $1 \mathrm{~g}$ each, from all fractions (magnetic, nonmagnetic, conductive, mixed, non-conductive). The samples were then dissolved with aqua regia at a ratio of 1:20 ( $1 \mathrm{~g}$ of printed circuit board sample to $20 \mathrm{ml}$ of aqua regia solution). The insoluble portions represent ceramics and polymers. The leached portion represents the soluble metals that were subsequently analyzed by inductively coupled plasma optical emission spectrometry (ICP-OES). Copper is the metal with the highest percentage amount in printed circuit boards due to its high electro conductivity. Chemical analysis showed that copper concentration in PCB-MP was 34.5 wt. \% [7]. The accuracy of chemical analysis for determining $\mathrm{Cu}$ and $\mathrm{Ni}$ in the printed circuit boards of mobile phones was influenced by granularity levels for the fractions $(\mathrm{d} \leq 1,250 \mu \mathrm{m})$ and for the fraction $(\mathrm{d} \leq 1,000 \mu \mathrm{m}) \mathrm{mm}$ without magnetic parts. A test sample of one $\mathrm{g}$ was taken from each sample for purposes of the chemical analysis. The $\mathrm{Cu}$ and $\mathrm{Ni}$ content (in \%) within PCBs was determined by the AAS method. Better accuracy to determine metals content was achieved in the fraction $(\mathrm{d} \leq 1,000 \mu \mathrm{m})[8]$.

Smelting was used as a method to homogenize samples of PCBs and MP prior to actual chemical analysis. The sample of PCBs was melted, cooled, and subsequently sieved into three particle-size distributions. Aliquot proportions of one $\mathrm{g}$ from each fraction $(2,000 \leq \mathrm{d} \leq 200$ $\mu \mathrm{m}),(\mathrm{d} \leq 200 \mu \mathrm{m})$, and $(\mathrm{d} \leq 2,000 \mu \mathrm{m})$ was weighed, which corresponded to the entire amount of PCBs. It was found that a representative example of mobile phone PCBs contained $16.92 \%$ of $\mathrm{Cu}, 1.30 \%$ of $\mathrm{Ni}$, and $380 \mathrm{~g} / \mathrm{t}$ of Au. A sample (one g) was dissolved in a solution of concentrated $\mathrm{HNO}_{3}$ and solution of concentrated $\mathrm{HCl}$, of diluted $\mathrm{H}_{2} \mathrm{SO}_{4}$ (one:one) with the addition of a few drops of HF. Copper was determined by the gravimetric method and the residual copper in the electrolyte was determined by atomic absorption spectrophotometry (AAS). Nickel and gold were determined by the AAS method [9]. Considering that the statistical dispersion is reaching zero value, this indicates that one can acquire better results as the sample is getting more homogeneous [10]. The authors dealt with the determination of metal content in PCBs of MPs using various methods in various modulation procedures in order to obtain a representative sample. The aim of this work was to determine the content of copper in representative samples of different grain sizes of PCBs, to statistically evaluate and to determine which granularity yields more accurate results in accordance with the standard deviation and variance. Based on the conclusions of the experimental work, it is possible to propose an optimal PCB sampling procedure from MT in order to determine the relevant amounts of metal.

\section{Material and Methods}

The input material used in this work was collected from different kinds of discarded push-button mobile phones. About $10.30 \mathrm{~kg}$ of collected mobile phones were used for the experiment. Batteries and plastic covers were dismantled by hand. Remaining PCBs were used for the experiment. Their total weight was $2 \mathrm{~kg}$. The crushing operation was carried out in a crusher hammer (type SK 600) down to fraction size of $(\mathrm{d} \leq 8,000 \mu \mathrm{m})$. A one $\mathrm{kg}$ sample was obtained by hand quartering, which was then divided 3 times by a divider. Magnetic separation was carried out to remove the magnetic fractions from the sample. Representative samples were milled into grain size less than one $\mathrm{mm}$ in the hammer mill (Hamilton Mich 49419) and subsequently sieved into the following grain fractions: $(\mathrm{d} \leq 1,000 \mu \mathrm{m}),(\mathrm{d} \leq 420 \mu \mathrm{m})$ and $(\mathrm{d} \leq 200 \mu \mathrm{m})$. The obtained one $\mathrm{g}$ test samples from each fraction were analyzed to determine the copper content

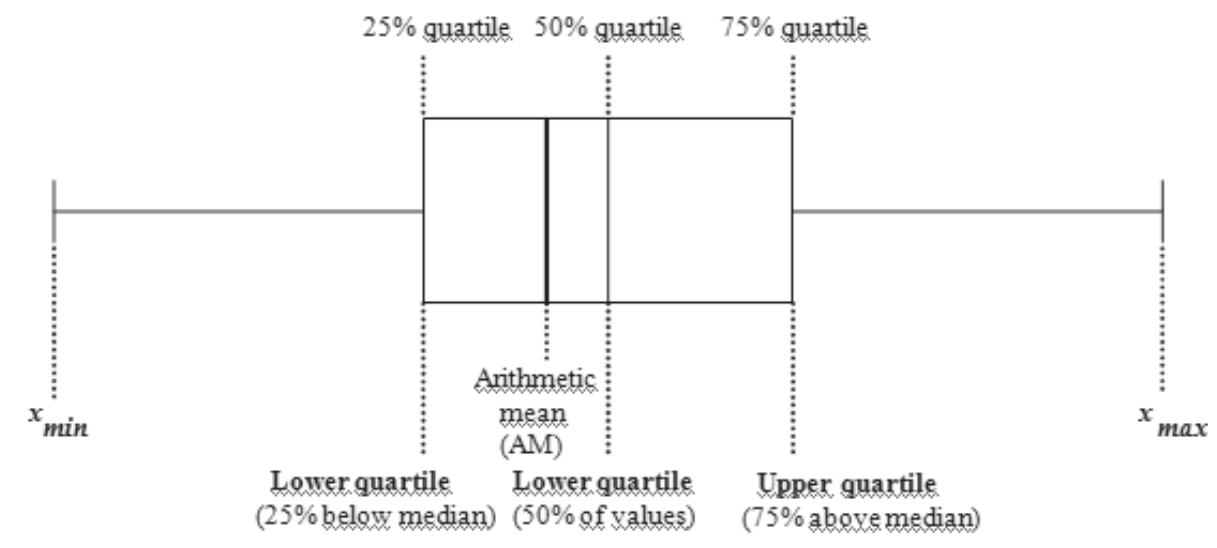

Fig. 4. Boxed graph [11]. 

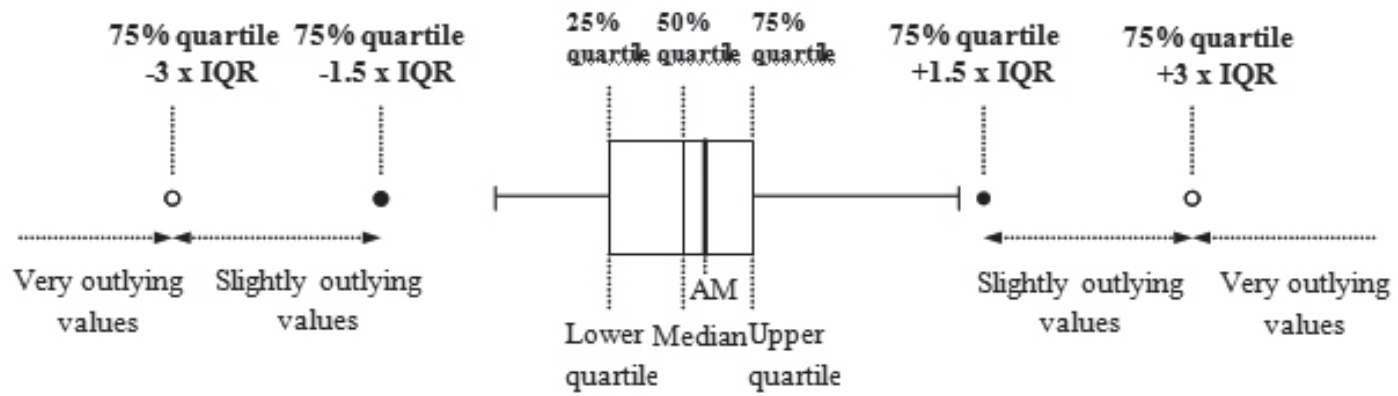

Fig. 5. Boxed graph with outlying values.

by atomic absorption spectrometry (AAS) (Varian Spectrometer AA $20+)$. The fraction $(\mathrm{d} \leq 2,000 \mu \mathrm{m})$ was also used to determine the content of $\mathrm{Cu}$. The average and scattering values were calculated, and the box plots were also prepared. Different grain fractions for chemical analysis are shown in Figs 1-3.

The selection of values for one random variable $\mathrm{X}$ has final range $\mathrm{n}$ and is denoted by $\mathrm{V}\left\{\mathrm{x}_{\mathrm{i}}\right\} \mathrm{n}$, (it is necessary to process $n$ values $x_{i}, i=1,2, \ldots, n$ - the selection of values $x i$ for range n). Processed values can be from different areas - quantitative in nominal terms, qualitatively in metrical volume terms. Values can be arranged (ranked, classified, categorized, sorted), but also unsorted (i.e., recorded as received). Values can be expressed in their measurement, but they can also be proportional, dimensionless data (percentages, etc.)

In this post we will work with a small selection with a number of values less than 30 . The partial goal of the contribution will be the calculation of the characteristics and the graphic representation of the selection.

The basic characteristic of position $\mathrm{V}\{\mathrm{xi}\}, \mathrm{n}<30$ is the arithmetic mean-average, the even distribution of "damage," "spoiled product," and "content of the relevant element in the sample" that is, simple average, calculated from all data:

$\bar{x}=\frac{1}{n} \cdot \sum_{i=1}^{n} x_{i}$ determines the focus of selection.

This average value, as a typical selection agent, has the following features:

- Impartiality, defiance.

- Asymptomatic impartiality $\lim _{n \rightarrow \infty} \bar{x}=X$ after repeated detection by measurement, $\overline{\mathrm{x}}$ is approaching $\mathrm{x}$.

- Simple cohesion, consistency $\lim _{n \rightarrow \infty} P[|X-\bar{x}| \varepsilon]=0$ with increasing $\mathrm{n}$ the error of the true value approximating to zero.

- Efficiency: $\sum_{i=1}^{n}\left(x_{i}-\bar{x}\right)^{2}=S_{1}=\min$,

- Minimum sum of squares of deviations from the mean, for $a \in\{x i\}: \sum_{i=1}^{n}\left(x_{i}-a\right)^{2}=S_{2} \geq S_{1}$

- Asympotic efficiency, sufficiency, at $n=n, \bar{x}=x$,

- Point estimate, determines the position of the center of gravity on the random variable axis.
The basic characteristic of the dispersion of values around its arithmetic mean is variance $\mathrm{s}^{2}$, which results from the efficiency of the arithmetic mean:

$$
\mathrm{s}^{2}=\frac{1}{(\mathrm{n}-1)} \cdot \sum_{\mathrm{i}=1}^{\mathrm{n}}\left(\mathrm{x}_{\mathrm{i}}-\overline{\mathrm{x}}\right)^{2}
$$

Since the variance in terms of the size of random variables is squared, it therefore increases the notion of variability of the random variable in the selection, introduces the derived characteristic, the standard deviation $\mathrm{s}$ as the root of the variance, that is, the magnitude of the respective random variable, $s= \pm \sqrt{s^{2}}$ or the average absolute deviation $\mathrm{d}=\frac{1}{\mathrm{n}} \cdot \sum_{\mathrm{i}=1}^{\mathrm{n}}\left|\mathrm{x}_{\mathrm{i}}-\overline{\mathrm{x}}\right|$.

Table 2. Chemical analysis of PCBs of MPs.

\begin{tabular}{|c|c|c|c|c|c|}
\hline $\begin{array}{l}\text { Grain size } \\
\quad(\mu \mathrm{m})\end{array}$ & & $\begin{array}{l}\mathrm{Cu} \\
(\%)\end{array}$ & $\begin{array}{l}\text { Grain size } \\
\quad(\mu \mathrm{m})\end{array}$ & & $\begin{array}{l}\mathrm{Cu} \\
(\%)\end{array}$ \\
\hline \multirow{8}{*}{$(d \leq 200)$} & 1 & 14.68 & \multirow{8}{*}{$(1,000 \leq \mathrm{d} \leq 200)$} & 1 & 31.57 \\
\hline & 2 & 14.60 & & 2 & 23.63 \\
\hline & 3 & 16.99 & & 3 & 19.50 \\
\hline & 4 & 16.90 & & 4 & 22.85 \\
\hline & 5 & 13.70 & & 5 & 26.99 \\
\hline & 6 & 13.75 & & 6 & 24.85 \\
\hline & 7 & 15.45 & & 7 & 26.00 \\
\hline & 8 & 14.59 & & 8 & 25.01 \\
\hline \multirow{8}{*}{$(\mathrm{d} \leq 420)$} & 1 & 30.36 & \multirow{8}{*}{$(d \leq 2,000)$} & 1 & 28.88 \\
\hline & 2 & 28.72 & & 2 & 31.24 \\
\hline & 3 & 24.86 & & 3 & 24.55 \\
\hline & 4 & 28.86 & & 4 & 25.48 \\
\hline & 5 & 28.39 & & 5 & 23.72 \\
\hline & 6 & 21.95 & & 6 & 24.40 \\
\hline & 7 & 31.77 & & 7 & 29.50 \\
\hline & 8 & 25.14 & & 8 & 27.47 \\
\hline
\end{tabular}


For the possibility of accurately comparing multidimensional random variables, the variation coefficient (variation coefficient) is calculated:

$$
\mathrm{V}_{\mathrm{x}}=\frac{\mathrm{s}}{\overline{\mathrm{x}}} \cdot 100[\%]
$$

...where $\mathrm{V}_{\mathrm{x}}$ is percentage fluctuations of the processed values.

The box and whisker plot is used to illustrate some of the selection characteristics of the set of $x i$ values,

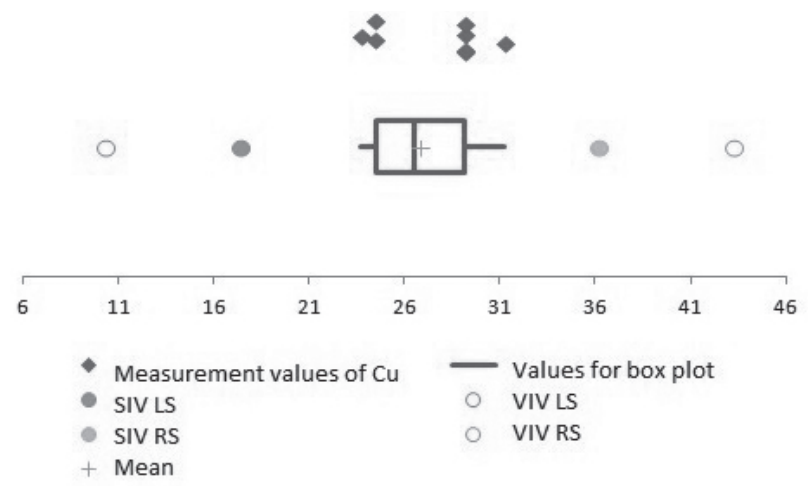

Fig. 6. Values $\mathrm{Cu}$ represented in box plot for the fraction $(\mathrm{d} \leq 2,000 \mu \mathrm{m}) \mathrm{N}=8$.

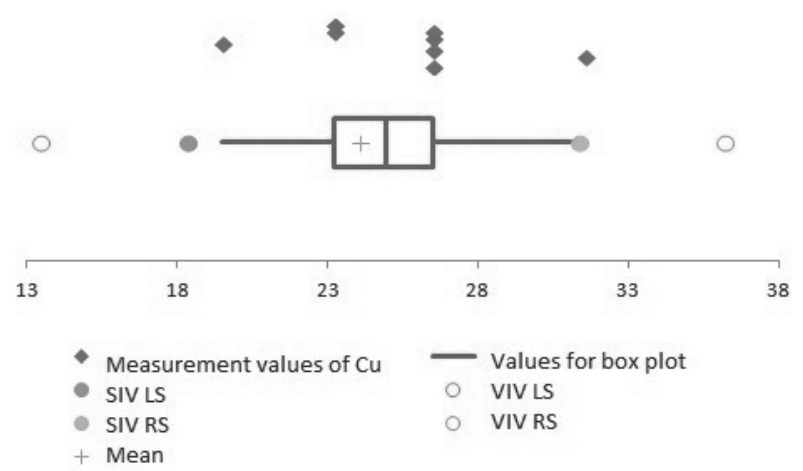

Fig. 7. Values $\mathrm{Cu}$ represented in box plot for the fraction $(1,000 \leq \mathrm{d} \leq 200 \mu \mathrm{m}) \mathrm{N}=8$.

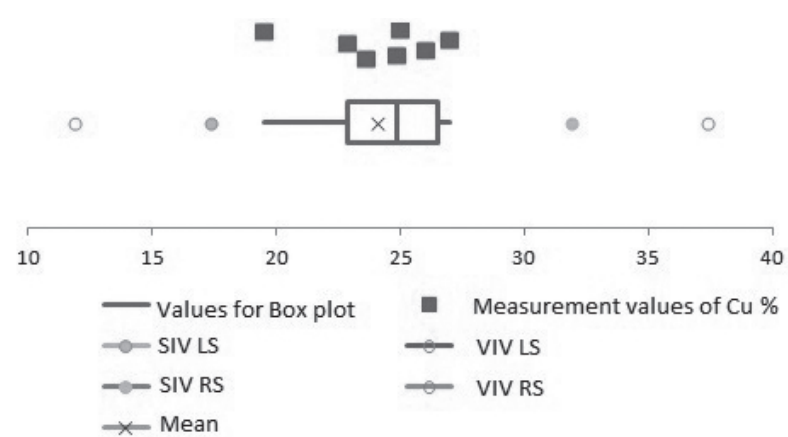

Fig. 8. Values $\mathrm{Cu}$ represented in box plot for the fraction $(1,000 \leq \mathrm{d} \leq 200 \mu \mathrm{m}) \mathrm{N}=7$. which is the result of its statistical processing. These characteristics include the minimum value, the first quartile (lower), the arithmetic mean, the median, the third quartile (upper), the maximum value, and possibly also the outlying values. In a simple box diagram, as can be seen in Fig. 4, the first and third quartiles limit the boundaries of the box. The area between these quartiles represents the interquartile range (IQR). The values of the first and fourth quartiles are denoted as segments

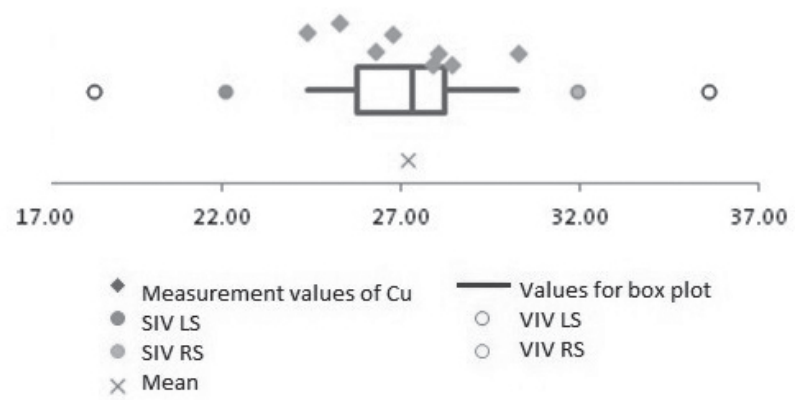

Fig. 9. Values $\mathrm{Cu}$ represented in box plot for the fraction $(\mathrm{d} \leq 420 \mu \mathrm{m}) \mathrm{N}=8$.

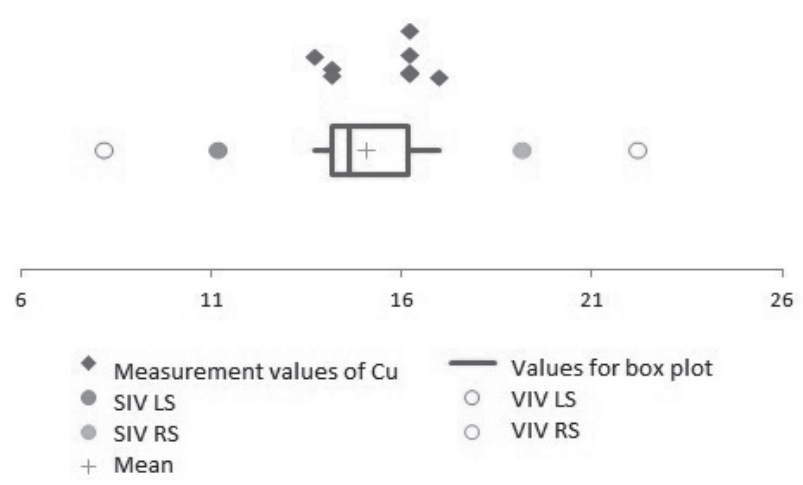

Fig. 10. Values $\mathrm{Cu}$ represented in box plot for the fraction $(\mathrm{d} \leq 200 \mu \mathrm{m}) \mathrm{N}=8$.

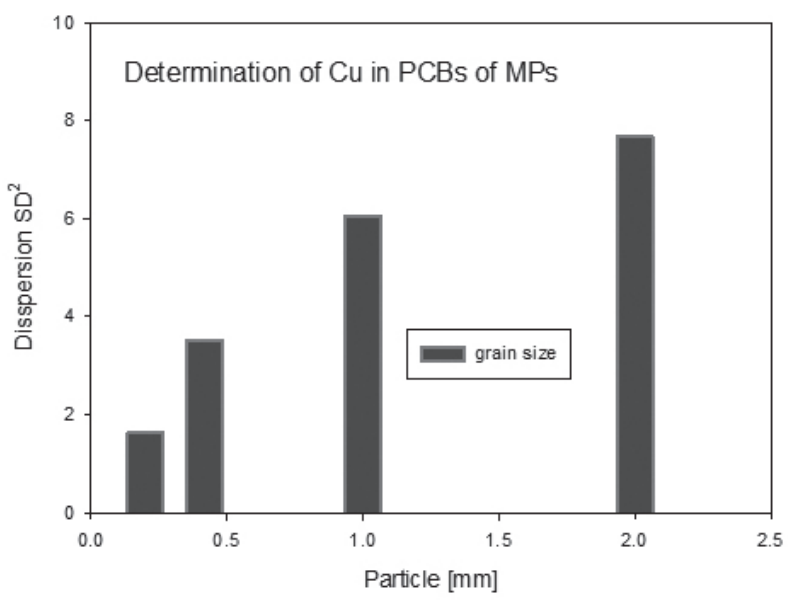

Fig. 11. Influence of PCB granularity on the accuracy of chemical analysis. 
Table 3. Comparison of statistical data for different grain fractions

\begin{tabular}{|c|c|c|c|c|}
\hline \multirow{2}{*}{$\begin{array}{c}\text { Statistical } \\
\text { characteris- } \\
\text { tics for } \mathrm{Cu}\end{array}$} & \multicolumn{4}{|c|}{ Grain size $(\mu \mathrm{m})$} \\
\cline { 2 - 5 } & $(\mathrm{d} \leq 2,000)$ & $(1,000 \leq \mathrm{d} \leq 200)$ & $(\mathrm{d} \leq 420)$ & $(\mathrm{d} \leq 200)$ \\
\hline Mean & 26.90 & 24.12 & 27.14 & 15.08 \\
\hline Dispersion & 7.67 & 6.05 & 3.53 & 1.62 \\
\hline $\mathrm{SD}$ & 2.77 & 2.46 & 1.88 & 1.27 \\
\hline $\mathrm{R}$ & 7.52 & 7.49 & 5.88 & 3.29 \\
\hline $\mathrm{V}_{\mathrm{x}}$ & 10.29 & 10.20 & 6.92 & 8.46 \\
\hline
\end{tabular}

(fusions) where the endpoints of the segments represent the minimum and maximum values.

For better clarity, a boxed outline graph is used (Fig. 5). The box is shown as in a simple box graph, but the fusions have a max. 1.5 times the IQR. Values that lie more than 1.5 times the IQR from the third quartile to the right or from the first quartile to the left represent slightly outlying values, and those that lie more than 3 times the IQR from the third quartile to the right or from the first quartile to the left represent very remote values. The boundary values for the slightly outlying values are marked with a full circle, and the boundary values for the very outlying values are marked with an empty circle [11].

\section{Results and Discussion}

The results of the chemical analysis to determine the content of $\mathrm{Cu}$ (in \%) in the four grain fractions of PCBs are shown in Table 2. The individual grain fractions were evaluated using Box Plots. The Grubbs test was performed and the mean value, standard deviation SD, variation range $\mathrm{R}$, and coefficient of variation $\mathrm{Vx}$ were calculated. In order to assess the symmetry and variability of data file and the existence of outliers or extreme values, a box plot was used as shown in Figs 6-10. The value of $31.57 \%$ for the fraction $(\mathrm{d} \leq 1,000 \mu \mathrm{m})$ indicated a gross measurement error (Fig. 7). To verify this assumption, the test of extreme values (Grubbs test) was applied only for the number of measurements $n \leq 30$. The calculated values of Grubbs test were: $\mathrm{T}_{\min }=1.87788, \mathrm{~T}_{\max }=3.0297$, and $\mathrm{T}_{\text {crit }}=2.172$. The minimum value calculation was correct; it was not burdened by a gross error. The maximum value, however, was incorrect; it was burdened by any gross error. For this reason, it was necessary to exclude the maximum value and repeat the test omitting this value $(\mathrm{N}=7)$ Fig. 8 .

\section{Q 2017 Martina taubertova Procedure of PCBs Sampling}

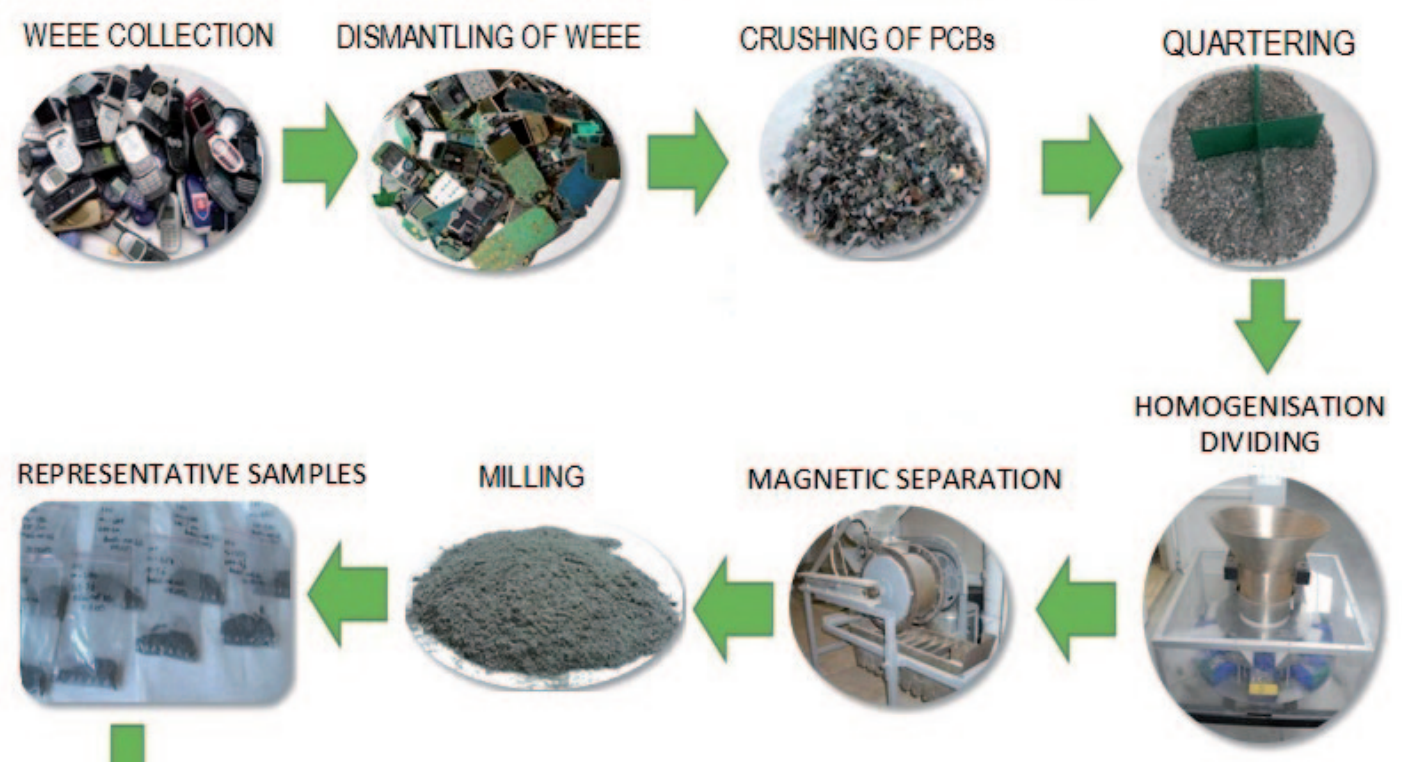

STATISTICAL EVALUATION OF THE RESULTS
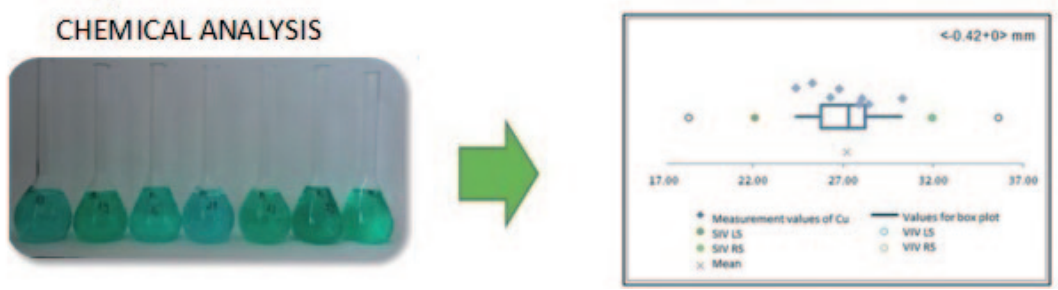

\begin{tabular}{|c|c|}
\hline $\mathrm{X}_{\mathrm{p}}$ & 27.14 \\
\hline $\mathrm{SD}^{2}$ & 3.53 \\
\hline $\mathrm{SD}$ & 1.88 \\
\hline $\mathrm{R}$ & 5.88 \\
\hline $\mathrm{V}_{\mathrm{z}}$ & 6.92 \\
\hline
\end{tabular}

Fig. 12. Flowsheet of PCB sampling 
For this reason, the number of $\mathrm{N}$ values in grain size 7 was determined. Other grain fractions were not burdened by errors and therefore the number of $\mathrm{N}$ values equals 8 as can be seen in Figs 9-10. In the box plot for $\mathrm{Cu}$, it is evident that the measured values do not interfere with the limit values and therefore the results are not errorfree and correct. In this case, the Grubbs test showed that the measurement did not contain any gross error and therefore it is possible to keep all the values in the range of variables. The influence of PCB granularity on the accuracy of chemical analysis is presented in Fig. 11. Statistical data of chemical analysis of both grain sizes - including standard deviation $\mathrm{SD}$, variation range $\mathrm{R}$, and coefficient of variation $\mathrm{Vx}$ - are shown in Table 3 . Based on the logistics of electronic waste sampling, the following procedure has been proposed (Fig. 12).

\section{Conclusions}

In this work we studied the influence of different grain size of representative samples on the accuracy of chemical analysis of printed circuit boards from mobile phones. From collected MPs, 10\% MT must be taken from which batteries and plastics were removed. The mechanically treated (crushed, milled) PCBs must be subsequently homogenized. From a representative sample by dividing (quartertering) sampled laboratory, samples were subjected to chemical analysis (AAS method) to determine $\mathrm{Cu}$ content as a main material in discarded PCBs. Based on the statistically evaluated results, we found that the greatest impact on PCB chemistry is granularity. In conclusion, it can be argued that the smaller the granularity, the lower the results scattering. The results were subject to a smaller error, i.e. were more accurate. From the conclusions of the experimental work, the smaller the grain size of a representative sample for chemical analysis, the higher the accuracy of determining the metals content within the sample. Chemical analysis of copper content (the highest metal content in PCBs) in the sample with grain size $(\mathrm{d} \leq 200 \mu \mathrm{m})$ was $15.5 \%$ and dispersion was 1.62 , which showed the highest accuracy of chemical analysis. This suggested procedure can also be used for further determination of material contents in PCBs such as $\mathrm{Au}, \mathrm{Ni}, \mathrm{Zn}$, and so on. These elements - namely $\mathrm{Au}, \mathrm{Ni}$, and $\mathrm{Zn}$ - will be the subject of the following research, the results of which will be published in subsequent articles.

\section{Acknowledgements}

This work was supported by the Slovak Research and Development Agency under grants VEGA 1/0442/17, VEGA 1/0631/17, and VEGA 1/0392/18.

\section{References}

1. DIRECTIVE 2002/95/EC OF THE EUROPEAN PARLIAMENT AND OF THE COUNCIL of 27 January 2003 on the restriction of the use of certain hazardous substances in electrical and electronic equipment.

2. TAKACOVA Z., ORAC D., HAVLIK T. Súčasné trendy v získavaní ušlachtilých kovov z vyradených dosiek plošných spojov (Current trends in the recovery of precious metals from discarded printed circuit boards) Odpady (Waste). 16 (3), 5, 2016 [In Slovak].

3. IEC 62321-2:2013. Determination of certain substances in electrotechnical products - Part 2: Disassembly, disjunction and mechanical sample preparation.

4. EXPLORING UMICORE PRECIOUS METALS REFINING, [cited 08. 04. 2017] Available on < http://ambientair. rec.org/documents/umicore.pdf>.

5. RECYCLING AURUBIS, [cited 10. 04. 2017] Available on $<$ https://www.aurubis.com/binaries/content/assets/ aurubis-en/dateien/product-documents/recycling-brochure 2013 eng_doppelseitig.pdf $>$.

6. KALINCOVA D., TAVODOVA M., KASTAN R. Inovation heat treatment of coining dies - Analysis of the microstructural parameters. Manufacturing technology: Journal for science, research and production. 16 (5), 946, 2016.

7. YAMANE L.H., de MORAES V.T., ESPINOSA D.C.R., TENÓRIO J.A.S. Recycling of WEEE: Characterization of spent printed circuit boards from mobile phones and computers. Waste Management. 31, 2553, 2011.

8. LAUBERTOVA M., MALINDZAKOVA M., ROSOVA A., TRPCEVSKA J. Material flow model of electronic waste sampling. Przemysł Chemiczny. 95 (7), 1390, 2016.

9. LAUBERTOVA M., TRPCEVSKA J., ZORAWSKI W., SMINCAKOVA E., PIROSKOVA M. Sampling procedure of printed circuit boards from discarded mobile phones. Metallurgy, materials and environment. 1, 2016.

10. MICKOVA V., REMETEIOVA D., RUZICKOVA S., DORKOVA M. Electronic Waste Processing for the Determination of Metals by Solution Analysis. 6th International Conference Quo Vadis Recycling, High Tatras 6-9 June 2017.

11. HEBAK P. Statisticke mysleni a nastroje analyzy dat (Statistical thinking and data analysis tools). 2015 [In Czech]. 
